Cell Research (2002); 12(5-6):311-320

http://www.cell-research.com

REVIEW

\title{
The role of nitric oxide in cancer
}

\author{
Weiming XU ${ }^{1, *}$, Li Zhi LIU ${ }^{1}$, Marilena LOIZIDOU ${ }^{2}$, Mohamed AHMED ${ }^{1}$, IAN G CHARLES ${ }^{1}$ \\ ${ }^{1}$ Wolfson Institute for Biomedical Research, Cruciform Building, Gower Street, UCL, London, WC1 E 6AU, UK \\ ${ }^{2}$ Department of Surgery, Charles Bell House, 67-73 Riding House Street, UCL, London W1W 7EJ, UK
}

\begin{abstract}
Nitric oxide (NO) is a pleiotropic regulator, critical to numerous biological processes, including vasodilatation, neurotransmission and macrophage-mediated immunity. The family of nitric oxide synthases (NOS) comprises inducible NOS (iNOS), endothelial NOS (eNOS), and neuronal NOS (nNOS). Interestingly, various studies have shown that all three isoforms can be involved in promoting or inhibiting the etiology of cancer. NOS activity has been detected in tumour cells of various histogenetic origins and has been associated with tumour grade, proliferation rate and expression of important signaling components associated with cancer development such as the oestrogen receptor. It appears that high levels of NOS expression (for example, generated by activated macrophages) may be cytostatic or cytotoxic for tumor cells, whereas low level activity can have the opposite effect and promote tumour growth. Paradoxically therefore, NO (and related reactive nitrogen species) may have both genotoxic and angiogenic properties. Increased NO-generation in a cell may select mutant p53 cells and contribute to tumour angiogenesis by upregulating VEGF. In addition, NO may modulate tumour DNA repair mechanisms by upregulating p53, poly(ADP-ribose) polymerase (PARP) and the DNA-dependent protein kinase (DNA-PK). An understanding at the molecular level of the role of $\mathrm{NO}$ in cancer will have profound therapeutic implications for the diagnosis and treatment of disease.
\end{abstract}

Key words: nitric oxide, oestrogen, cancer, p53, PARP, DNA-PKcs.

\section{INTRODUCTION}

Over the past decade or so, it has become evident that the free radical gas nitric oxide (NO) acts as a novel transcellular messenger molecule in many key

* Corresponding author: Dr. Weiming XU, Wolfson Institute for Biomedical Research. University College London, Cruciform Building, Gower Street, London WC1E 6AU.UK.

Fax: $442078132846 \quad$ Tel: 442076796209

Email:w.xu@ucl.ac.uk.

Abbreviations: NO, nitric oxide; NOS, nitric oxide synthase; iNOS, inducible nitric oxide synthase; eNOS, endothelial nitric oxide synthase; nNOS, neuronal nitric oxide synthase; PARP, poly(ADP-ribose) polymerase; DNA-PK, DNA-dependent protein kinase; DNA-PKcs, catalytic subunit of DNA-PK; BH4, tetrahydrobiopterin; FAD, flavin adenosine dinucleotide; FMN, flavin mononucleotide; sGC, soluble guanylate cyclase; VEGF, vascular endothelial growth factor. physiological and pathological processes[1]. NO plays a central role in the cardiovascular system as the endothelium - derived relaxing factor[2-5]. Within the central nervous system, NO is a crucial component of the signal transduction pathways used for memory formation, sensory processing, and the regulation of cerebral blood flow[6]. Interestingly, as early as 1982, NO was implicated in the immunodefence network, as marked increase in urinary $\mathrm{NO}_{3}^{-}$ excretion was observed in human subjects with diarrhoea and fever[7], [8]. Further work showed that the blood levels and urinary excretion of $\mathrm{NO}_{3}^{-}$increased after exposure to Escherichia coli lipopolysaccharide (LPS) in LPS-sensitive mice and that acti- 
vated mouse peritoneal macrophages showed increased $\mathrm{NO}_{2}^{-}$and $\mathrm{NO}_{3}^{-}$production in vitro[9]. The mammalian immuno -defense network is involved in tumour suppression, and macrophages are an important part of this process because of their ability to destroy selectively a broad range of tumour types upon specific activation. The role of NO in macrophage cytotoxicity was first described by Hibbs and colleagues in 1987[10], and since that time numerous studies have shown that cytokine activated rodent macrophages can generate large concentrations of NO by up-regulation of expression of the inducible nitric oxide synthase gene (iNOS)[11]. The NO generated by this process is capable of killing a range of tumour cells of differing origin and grade[11-15]. Various direct and indirect mechanisms have been proposed for the anti-tumour properties of NO. Mechanisms include direct damage of DNA, inhibition of DNA synthesis and inhibition of the ratelimiting enzyme ribonucleotide reductase. Reduced activity of cis-aconitase and loss of a large fraction of the iron pool, have also been suggested as possible mechanisms. Importantly, NO-generation can efect mitochondrial physiology leading to reduction of $\mathrm{O}_{2}$ consumption and damage to complexes I and II in the mitochondrial electron transport chain, reversible inhibition of complex IV activity and induction of apoptosis[10-15].

Importantly, various studies have shown that all three isoforms of NOS, (iNOS, eNOS and nNOS), have been detected in tumour cells from a wide range of isolates[16-18]. NOS activity has been observed in human tumour cell lines and cells from tumour biopsies. However, the precise function(s) of NO in tumour biology remains unclear, and several lines of research have indicated that NO may have dual effects in cancer. In this review, we will present some recent evidence on both the pro- and anti-tumour activities of $\mathrm{NO}$ and discuss the implications of these data on the use of NO as a therapeutic agent for the treatment of cancer.

\section{Nitric oxide generation and its biological targets}

NO is a diatomic free radical molecule, and is a gas at room temperature. Within mammalian cells a family of NOS enzymes has been shown to be able to generate $\mathrm{NO}$, and all family members require a panel of substrates and co-factors to be fully functional. For example, the NO-generating reaction requires L-arginine, NADPH and oxygen as substrates, and tetrahydrobiopterin (BH4), thiol, flavin adenine dinucleotide (FAD), and flavin mononucleotide (FMN) as cofactors. In addition to NO, the NOS-catalysed reaction produces citrulline and NADP as coproducts.

Three different isoforms of the NOS family have been identified; endothelial NOS (eNOS), neuronal NOS (nNOS) and inducible NOS (iNOS). The gene symbol nomenclatures are: NOS1 for nNOS, NOS2 for iNOS and NOS3 for eNOS[6]. The nNOS and eNOS isoforms are constitutively expressed in a variety of cell types including the endothelium, platelets, and neurons. Typically, the constitutive NOS isoforms can be activated as a result of calmodulin (CaM) binding following a rise in intracellular calcium. They may also be activated and/or inhibited by phosphorylation via various protein kinases. Unlike nNOS and eNOS, iNOS displays a high affinity for CaM, which is tightly bound within physiological concentrations of calcium. As a consequence of this, the activation of iNOS is not calciumdependent. However, the expression of iNOS can be transcriptionally regulated by factors such as cytokines (e.g. interferon- $\gamma$ (IFN- $\gamma$ ), interleukin-1 $\beta$ (IL-1 $\beta$ ) and tumour necrosis factor- $\alpha$ (TNF- $\alpha$ ), bacterial endotoxin (LPS) and oxidative stress (e.g. under conditions encountered during hypoxia).

A good starting point to assess the function of $\mathrm{NO}$ in mammalian physiology is to examine its chemical properties. NO is a gas at room and body temperature, making it highly diffusible within the vasculature. As NO is a free radical, it is a highly reactive molecule within biological systems, reacting with other free radicals, molecular oxygen and heavy metals. It has been suggested that the biological effects of $\mathrm{NO}$ can be mediated by the products of different NO metabolites. For example, NO can react rapidly in the intracellular environment to form nitrite and nitrate, S-nitroso-thiols or peroxynitrite. These metabolites may play a key role in mediating many of the key genotoxic effects, (such as DNA damage), that are associated with the generation of NO. Importantly, NO has been shown to bind 
rapidly, and with high affinity, to ferrous iron $\left(\mathrm{Fe}^{2+}\right)$. As a consequence of this, NO can bind easily to free iron, iron within iron-sulphur centres, and iron within haemoproteins (especially when the haem contains a free ligand position). Many of the biological processes described for NO (involving smooth muscle relaxation, neurotransmission, and inhibition of platelet aggregation and adhesion) results from NO binding to the ferrous haem iron of the enzyme soluble guanylate cyclase (sGC), which in turn results in an increase in cGMP production. Due its association with haem centres it is not surprising that the binding of NO to haemoglobin is regarded as a significant route by which NO can be broken down in the body.

NO can cause DNA damage via the generation of peroxynitrite (ONOO-) and $\mathrm{N}_{2} \mathrm{O}_{3}$. Peroxynitrite can oxidise and nitrate DNA and may potentially cause single-strand DNA breaks through attack on the sugar-phosphate backbone. $\mathrm{N}_{2} \mathrm{O}_{3}$ can nitrosate amines to form $\mathrm{N}$-nitrosamines, then alkylate DNA. Nitrosation of primary amines, (e.g. in DNA bases) leads to the formation of diazonium ions and subsequent deamination and DNA-crosslinks. The wide range of differing biological effects arising from exposure to NO is very much dependent upon many factors, such as formation and metabolism of NO, the type of NOS enzymes that are present, the interaction between NO utilising processes, and crucially the concentration of $\mathrm{NO}$ that is present in the given system.

\section{Nitric oxide synthase expression in tumours}

The iNOS isoform has been mostly studied for its role in immuno-mediated processes, for example, iNOS knock-out mice have been generated and shown to have increased susceptibility to infections [18]. The first NOS isoform implicated in the macrophage-mediated tumour killing process was also iNOS, and as a consequence this isoform has been at the center of attention for study of its expression in cancer. In normal (non-tumourogenic) cells, iNOS has been detected in macrophages and neutrophils, as well as in hepatocytes, cardiac myocytes, chondrocytes and many other cell types. Recently, lack of iNOS in knock-out mice has been found to promote intestinal tumorigenesis in the $\mathrm{Apc}(\mathrm{Min} /+)$ colon cancer mouse model, thereby substantiating the role of iNOS within host defence mechanisms[19].

An initial study on iNOS expression in human breast cancer suggested that iNOS activity was higher in less differentiated tumours in a panel of 15 invasive breast carcinomas[17]. iNOS expression could be detected predominantly in peritumoural and intratumoural macrophages. NO biosynthesis was significantly greater for grade III tumours as compared with grade II in specimens from 10 breast cancer tissues. Recently, three relatively large scale studies [20-22], suggested that iNOS is not only expressed in stromal cells and macrophages in the tumour, but also in tumour cells themselves (Tab 1). Reveneau et al reported NOS activity in 27 of 40 tumours studied [20]. Vakkala et al showed that carcinomas with both iNOS positive tumour and stromal cells had a higher apoptotic index and a higher calculated microvessel density index[21]. Loibl et al further demonstrated that while none of the benign lesions were positive for iNOS, $67 \%$ in situ carcinomas and $61 \%$ invasive lesions showed iNOS tumour cell staining. eNOS expression was found in 33 invasive lesions (61\%)[22]. Both iNOS expressing lesions and eNOS expressing lesions showed strong co-expression $(\mathrm{p}=0.0008)$.

Tab 1. Incidence of iNOS expression in benign, in situ and invasive breast lesions

\begin{tabular}{|c|c|c|c|c|c|c|}
\hline Studies(reference) & $\begin{array}{c}\text { No. of benign } \\
\text { lesion( } \%)\end{array}$ & & $\begin{array}{c}\text { No. of in situ } \\
\text { carcinomas(\%) }\end{array}$ & & $\begin{array}{l}\text { No. of invisive } \\
\text { carcinomas(\%) }\end{array}$ & \\
\hline & Negative* & Positive & Negative* & Positive & Negative* & Positive \\
\hline Thomsen et al(17) & $8(100)$ & $0(0)$ & - & - & $3(20)$ & $12(80)$ \\
\hline Reveneau et al(20) & $8(100)$ & - & - & - & $13(30)$ & $27(70)$ \\
\hline Vakkala et al(21) & - & - & $23(53)$ & $20(47)$ & $28(41)$ & $40(59)$ \\
\hline Loibl et al(22) & $41(100)$ & $0(0)$ & $3(33)$ & $6(67)$ & 21(39) & $33(61)$ \\
\hline
\end{tabular}

*negative or very low enzyme activities $\left(<0.7 \mathrm{pmol} \mathrm{min}^{-1} \mathrm{mg}^{-1}\right.$ protein $)$ 
In our recent studies, we have also found strong coexpression of iNOS and eNOS in in situ ductal carcinomas[23]. Using an antibody raised against a C-terminal peptide of iNOS we demonstrate that there is considerable iNOS expression, not only in the surrounding stroma, but also within the in situ ductal carcinoma itself (Fig 1a) as compared with preimmune rabbit serum control (Fig 1b). Interestingly, in consecutive sections, strong immunopositivity can also be detected with an-eNOS antibody, mainly in the stromal cells, but also in some tumour cells (data not shown). These findings are similar to those reported by Vakkala et al[24] who showed that eNOS was expressed in $65 \%$ of samples

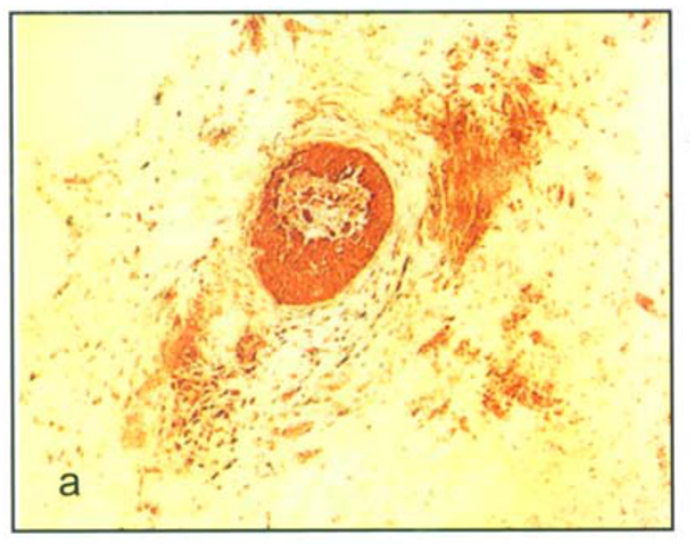

iNOS immnoperoxidase staining

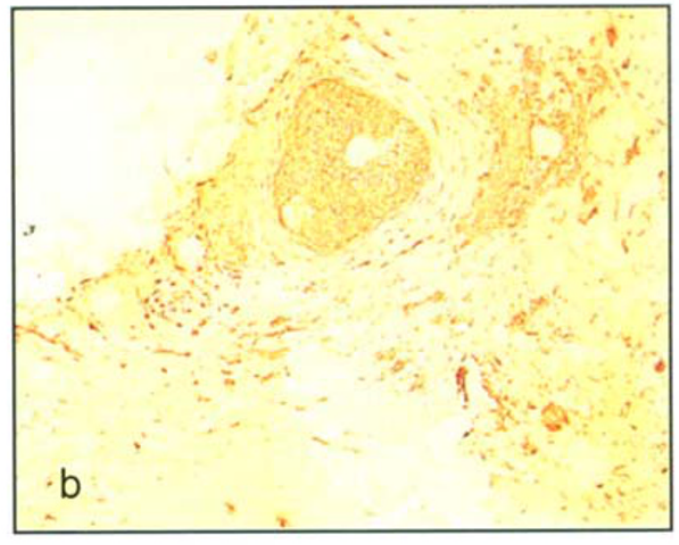

Preimmune rabbit serum staining

Fig 1. (a) Section of human in situ ductal carcinomas (frozen sections) immnuocytochemically stained for human iNOS C-terminal peptide antibody[50]. (b)is a control which has been stained using preimmune rabbit serum. Solid arrow indicates in situ carcinoma. Dashed arrow indicates surrounding stroma cells. $\times 100$

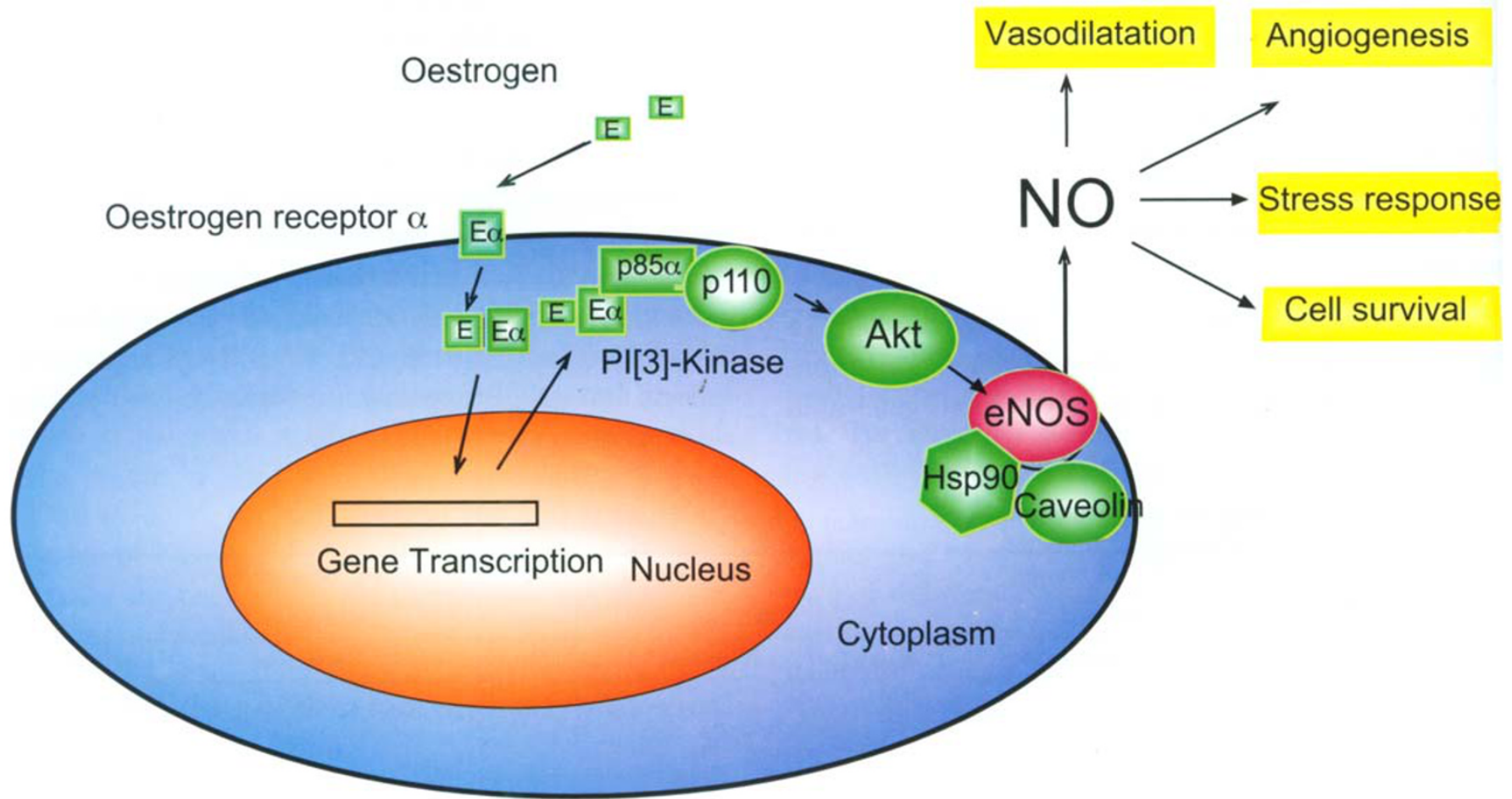

Fig 2. Schematic presentation of pathway mediating indirect activation of eNOS by oestrogen. 
(80 cases in total) with immunopositivity seen both in stromal structures and carcinoma cells[24]. Interestingly, Martin et al recently reported a significant positive correlation between the percentage of tumour cells with eNOS expression and oestrogen receptors[25]. We have also observed that some eNOS positive in situ ductal carcinomas show positive staining with antibody to estrogen receptors $(\mathrm{Xu}$ et al unpublished data). Recently several studies have shown that the oestrogen/oestrogen receptor complex binds to the p85a regulatory subunit of phosphatidylinositol-3-OH kinase (PI-(3)K), which leads to activation of protein kinase B/Akt [26], [27]. It is known that the catalytic activity of eNOS is augmented by phosphorylation of a C-terminal serine residue (Ser-1177 of human eNOS) through the PI(3)K/Akt pathway[28],[29]. Therefore, it is possible that oestrogen acting on the oestrogen receptor (ER $\sigma)$ located on the surface of cell membranes, could indirectly activate the release of $\mathrm{NO}$ from membrane bound eNOS (Fig 2). It is possible that the NO generated from this activation of eNOS may contribute significantly to tumour cell survival under hypoxia and other stress conditions. It should be noted that there are complicated signalling network(s) in endothelial cells capable of regulating eNOS activity. For example, the Akt-mediated phosphorylation activity can be enhanced by binding to heat shock protein-90[30] and inhibited by binding to Caveolin-1 [31][Fig 2].

In addition to breast cancer, iNOS has also been shown to be markedly expressed in approximately $60 \%$ of human adenomas and in $20-25 \%$ of colon carcinomas, while expression was either low or absent in the surrounding normal tissues[32], [33]. In human ovarian cancer, iNOS activity has been localized in tumour cells and not found in normal tissue [16]. Other tumours that have demonstrated iNOS gene expression are brain[1][34], head and neck[35], esophagus[36], lung[37], prostate[38], bladder[39], pancreatic[40], and Kaposi' s sarcoma[41].

In the central nerve system, $\mathrm{NO}$ has a variety of biological functions including vasorelaxation and neurotransmision. Interestingly, nNOS has been detected in some oligodendroglioma and neuroblastoma cell lines, althouth further studies are needed to clarified the role of nNOS in tumour pathology [34].

\section{NO and tumour cell angiogenesis}

While NO had been shown to have anti-tumour $\mathrm{p}$ roperties[10], Jenkins et al[42][1995] first reporte $\mathrm{d}$ the surprising finding that human carcinoma cells transfected with a murine iNOS cDNA cassette (DL D-1 cells generating 20 pmol min- 1 mg- 1 NOS activ ity) showed increased tumour growth, rather than $d$ ecreased growth. Using a nude mouse/xanograft mo del it was shown that growth of these NO-generatin $\mathrm{g}$ tumours was accompanied by increased neovascul arization. These results were supported by Ambs et al, who used recombinant iNOS expressing Calu-6 a nd HT-29 human carcinoma cell lines containing $m$ utant p53[43] to look at tumour growth. The author s demonstrated that an NO-mediated up-regulation of VEGF corresponded with increased vascularisati on in the xenograft tumours. Therefore it is possibl e that NO generated by NOS (located either within $\mathrm{t}$ he tumour or in the surrounding stroma) may prom ote new blood vessel formation by up-regulating VE GF. This neovasculaturization not only enhances th e ability of the tumour to grow, but also increases it $\mathrm{s}$ invasiveness and metastatic ability.

\section{NO, p53, PARP and DNA-PKes in DNA re- pair}

As NO is a free radical, it is a highly reactive molecule within biological systems, capable of interaction with other free radicals, molecular oxygen and heavy metals. The biological effects of NO can be mediated by the products of different $\mathrm{NO}$ metabolites. For example, NO rapidly reacts intracellularly to form nitrite and nitrate, S-nitroso-thiols or peroxynitrate, and these metabolites are believed to play key roles in mediating many of the NO-associated genotoxic effects. These effects include DNA damage, which can be initiated by nitrosative deamination, DNA strand breakage or DNA modification[44].

One of the consequences of the NO- mediated DNA damage is to trigger p53 accumulation, which can induce apoptosis. This is a possible process by which NO may induce death of tumour cells. An increase in NOS activity (arising from increased transcriptional activity, or from post-transcriptional/protein regulation activity) in tumour cells can consequently cause the concentration of NO to be elevated 
such that it triggers p53-mediated growth arrest and apoptosis[45],[46]. Interestingly, it has been demonstrated that accumulation of p53 results ultimately in down-regulation of iNOS expression by inhibition of iNOS promoter activity[47]. Thus a negative feedback loop is formed between NO-generation and p53 accumulation, that may constitute part of a physiological mechanism, which responds to endogenously produced DNA damage due to NO. Overall, this p53-mediated growth inhibition may be expected to provide a strong selection pressure for mutant p53 expression in tumor cells.

In addition to p53, NO has also been shown to activate poly (ADP-ribose) polymerase (PARP) [48] and it has been proposed that this activation is due to DNA damage. This damage may take the form of DNA strand breaks or nitrosative deamination of DNA bases when NO is generated at high concentrations. These high concentrations of NO have been reported for NMDA-mediated neurotoxicity as well as for tumouricidal and bactericidal activation of cells[44]. Another important DNA repair enzyme, DNA-dependent protein kinase (DNA-PK), is also known to be essential for the maintenance of the structural integrity of the genome. DNA-PK is a serine/threonine protein kinase consisting of a large catalytic subunit (DNA-PKcs) and a regulatory subunit $(\mathrm{Ku})$. Recently, mammalian DNA-PKcs has been shown to be an essential component of the DNA double-strand repair pathway, as well as being crucial for $\mathrm{V}(\mathrm{D}) \mathrm{J}$ recombination, involved in the generation of immunoglobulin and T-cell diversity. Scid mice, which lack DNA-PKcs, show increased susceptibility to ionising radiation in addition to having impaired V(D)J recombination and arrested T- and B-cell development[49]. Interestingly, although DNA-PK activity cannot be up-regulated by strong doses of radiation, we found that NO can act a signal, increasing the activity of DNA-PK. Importantly, we showed that this increase occurred by transcriptional up-regulation of DNA-PKcs expression and occurred under physiologically relevant ranges of $\mathrm{NO}$ concentrations[50]. Biologically, this NO-mediated increase in enzymatically active DNA-PK not only protected cells from the toxic effects of NO, but also provided cross-protection against clinically important DNAdamaging agents, such as X-ray radiation, adriamycin, bleomycin and cisplatin[50].
The NO-mediated increase in DNA-PKcs pathway not only plays an important role in tumour DNA repair[51], but may also play an important role in other tissue damage processes which involve NOmediated stress[52],[53]. For example, failing myocardium, (advanced heart failure due to idiopathic dilated cardiomyopathy) undergoes active DNA repair, where DNA-PKcs expression is strongly correlated with iNOS expression $(\mathrm{r}=0.53, \mathrm{p}<0.01)$ [53]. Given the fact that one of the major substrates of DNA-PKcs is p53[54] and DNA-PKcs itself is subjected to ADP-ribosylation by PARP, it is possible that NO-mediated DNA damage and repair could play a significant role in tumour development (Fig 3).

\section{NO as a therapeutic agent for the treat- ment of cancer}

NO-based therapeutics can be traced back for more than a centrury when Willaim Murell proposed the sublingual application of nitroglycerin as a remedy for angina pectoris[55]. From the time of discovery of the vasodilatory properties of the organic nitrates and nitrites, it took more than hundred years to elucidate their mode of action at the molecular level. For example, it was not until 1987 that NO gas was identified both as the endogenous endothelium-derived relaxing factor[3-5], and as being involved as a primary defence mechanism against tumour cells and intracellular microorganisms[10].

Several laboratories have demonstarted that NOreleasing agents can kill tumour cells, and as a consequence there have been attempts deliver NO to cells. While NO-releasing drugs are under developement, an attractive alternative mechanism for delivery would be to transfer NOS- encoding cDNA sequences into cancer cells for gene therapy purposes. Several studies have shown that this approach may work. For example, using a mouse model it was demonstarted that transfection of K-1735 melanoma cells with an iNOS cDNA expression cassette suppressed tumourogenicity and abrogated metastasis[14]. Transfection of human renal carcinoma cells with a retroviral iNOS cassette showed similar results[15]. A problem with current approaches however is that constitutive expression of NOS can quickly result in death of the transfectant, shortening the time that NO can be generated, and 
potentially limiting the utility of the approach. NOS transfectants often have to be cultured under conditions that reduce toxicity (for example in the presence of a NOS inhibitor), and transfection attempts may result in cells that are capable of relatively low levels of NO-generation[43]. As discussed above, this may result in concentrations of NO that promote tumour growth rather than cell killing. Another significant point is that NOS enzyme activity requires a panel of substrates and co-factors for full activity, and these may be missing from the target cell type. For example synthesis of the important co-factor tetrahydrobiopterin $(\mathrm{BH} 4)$, requires transcriptional regulation of the rate- limiting enzyme GTPcyclohydrolase, which may not be induced in all target cells[56]. Lastly, both retroviral and adenoviral vector maybe hazardous to the host and pose a major health and safety risk[57].

A potential strategy to overcome the problems

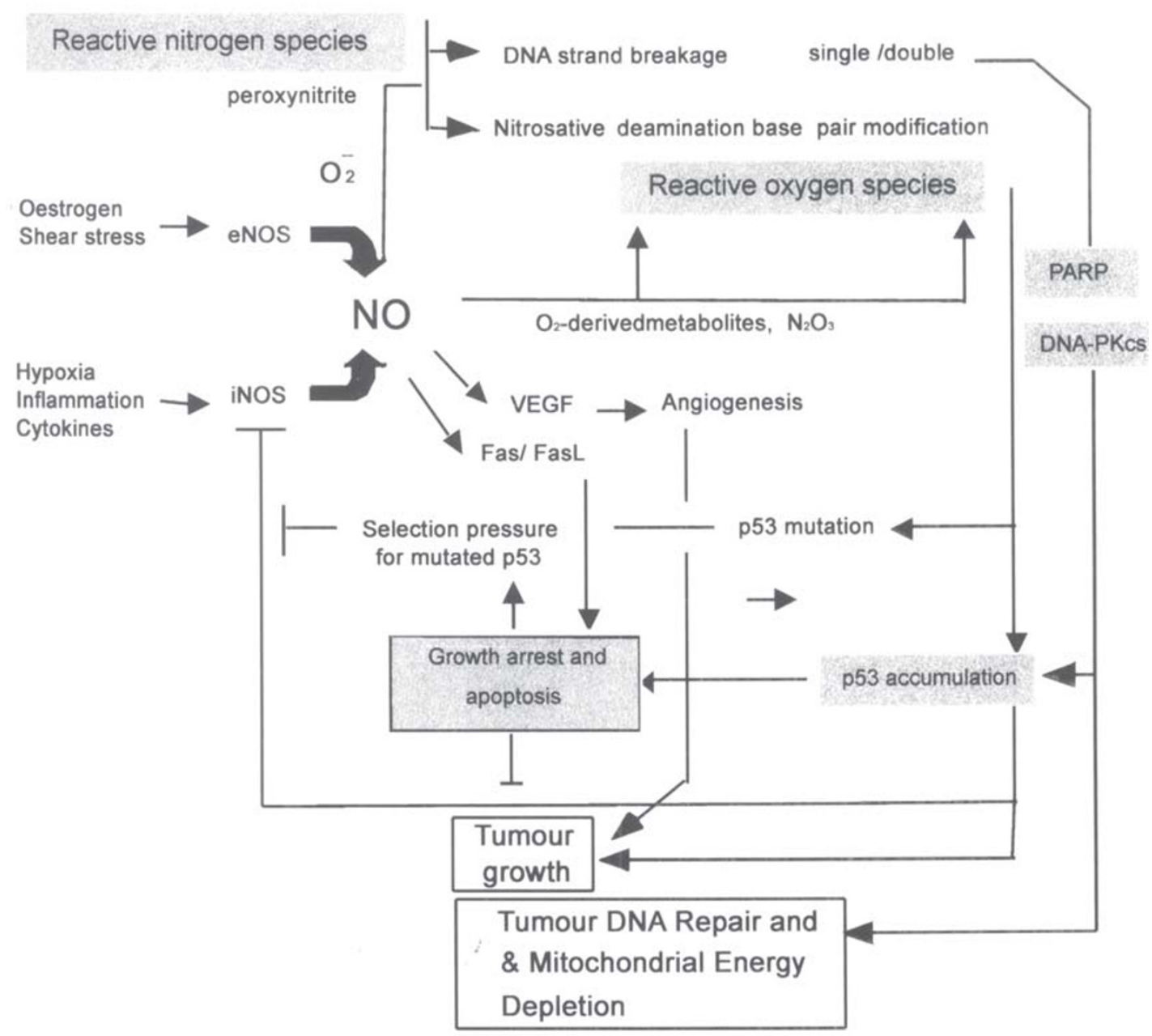

Fig 3. A representation of the dual action of nitric oxide on tumour growth

associated with gene therapy is to use a cell-based approach. Cell-based approaches utilise the delivery of recombinant cells (rather than genes) to the target site, with the advantage that the expression of the gene of interest can be optimised prior to delivery. For example, we have recently shown the utility of two novel iNOS-expressing human cell lines that can generate high concentrations of NO following treatment with analogues of either the insect hormone ecdysone or tetracycline[50],[58]. In order to make the NO- generating cells suitable for therapeutic delivery they have been encapsulated within a semipermeable alginate-poly-L-lysine membrane. Encapsulated cells are protected from environmental 
stresses encountered in the host (such as the host immune response) and can be delivered to tumour site(s) in a nude mouse model[58],[59]. Following delivery, high concentrations of NO and reactive nitrogen species can be generated by administration of the appropriate inducer. This approach has been very successful, and we have used it in a tumour model showing $100 \%$ killing of SKOV-3 tumours and 54\% killing of DLD-1 tumours[58]. Importantly, this strategy allowed the mechanism of tumour killing to be determined as it was shown that tumour killing was associated with concomitant up-regulation of the Fas/FasL proteins. Overall we believe that the cell-delivery approach addresses some of the shortcomings of competing strategies and has the potential to inhibit or kill many different types of tumours from various histological origins[60].

\section{CONCLUSION}

The discovery of the generation of $\mathrm{NO}$ by mammalian tissues and the elucidation of some of its biological roles in cancer has thrown new light onto many areas of tumour biology research. Although initial findings suggested that the immune-cell generated NO is cytostatic or cytotoxic for tumour cells, later findings have shown that $\mathrm{NO}$ can also possess apparently contradictory activity leading to increased tumour growth. NO can contribute to tumour angiogenesis by upregulating VEGF and modulating tumour DNA repair mechanism(s) by up-regulating p53, PARP and DNA-PKcs. Overall, we can safely say that NO is a 'Doubled-Edged Sword' in cancer. On the one hand, high concentrations of NO, (for example, generated by activated macrophages) may mediate cancer cell apoptosis and the inhibition of cancer growth. On the other hand, at (relatively) low concentrations of NO, (for example, at concentrations measurable in many different types of clinical cancer samples), tumour growth and proliferation is promoted. The regulation of tumour growth by NO represents an important new dimension in cancer research. Further work into the precise mechanisms of this process is required to help us develop new therapeutic tools for the treatment of cancer.

\section{ACKNOWLEDGMENTS}

We would like to thank the Medical Research
Council (UK) for their support.

\section{REFERENCES}

[1] Moncada S, Palmer RM, Higgs EA. Nitric oxide: physiology, pathophysiology, and pharmacology. Pharmacol Rev 1991; 43:109-42.

[2] Furchgott RF, Zawadzki JV. The obligatory role of endothelial cells in the relaxation of arterial smooth muscle by acetylcholine. Nature 1980; 288:373-6.

[3] Ignarro LJ, Buga GM, Wood KS, Byrns RE, Chaudhuri G. Endothelium-derived relaxing factor produced and released from the artery and vein is nitric oxide. Proc Natl Acad Sci USA 1987; 84:9265-9.

[4] Katsuki S, Arnold W, Mittal C, Murad F. Stimulation of guanylate cyclase by sodium nitroprusside, nitroglycerin and nitric oxide in various tissue preparations and comparison to the effects of sodium and hydroxylamine. J Cyclic Nucleotides Res 1977; 3:23-5.

[5] Palmer RM, Ferrige AG, Moncada S. Nitric oxide release accounts for the biological activity of endothelium-derived relaxing factor. Nature 1987; 327:524-6.

[6] Xu W, Liu L. Nitric Oxide: from a mysterious labile factor to the molecule of the Nobel Prize. Recent progress in nitric oxide research. Cell Research 1998; 8:251-8.

[7] Wagner DA, Young VR, Tannenbaum SR, Schultz DS, Deen WM. Mammalian nitrate biochemistry: metabolism and endogenous synthesis. IARC Sci Publ 1984; 57:247-53.

[8] Hegesh E, Shiloah J. Blood nitrates and infantile methemoglobinemia. Clin Chim Acta 1982; 125:107-15.

[9] Stuehr DJ, Marletta MA. Mammalian nitrate biosynthesis: mouse macrophages produce nitrite and nitrate in response to Escherichia coli lipopolysaccharide. Proc Natl Acad Sci USA 1985; 82:7738-42.

[10] Hibbs JB Jr, Taintor RR,Vavrin Z. Macrophage cytotoxicity: role for L-arginine deiminase and imino nitrogen oxidation to nitrite. Science 1987; 235:473-6.

[11] MacMicking J, Xie QW, Nathan C. Nitric oxide and macrophage function. Annu Rev Immunol 1997; 15:323-50.

[12] Xu L, Xie K, Fidler IJ. Therapy of human ovarian cancer by transfection with the murine interferon beta gene: role of macrophage-inducible nitric oxide synthase. Hum Gene Ther 1998; 9:2699-708.

[13] Garban HJ and Bonavida B. Nitric oxide sensitizes ovarian tumor cells to Fas-induced apoptosis. Gynecol Oncol 1999; 73:257-64.

[14] Xie K, Huang S, Dong Z. et al. Transfection with the inducible nitric oxide synthase gene suppresses tumorigenicity and abrogates metastasis by K-1735 murine melanoma cells. J Exp Med 1995; 181:1333-43.

[15] Juang SH, Xie K, Xu L, et al. Suppression of tumorigenicity and metastasis of human renal carcinoma cells by infection with retroviral vectors harboring the murine inducible nitric oxide synthase gene. Hum Gene Ther 1998; 9:845-85.

[16] Thomsen LL, Lawton FG, Knowles RG, Beesley JE, Riveros-Moreno V, Moncada S. Nitric oxide synthase 
activity in human gynecological cancer. Cancer Res 1994; 54:1352-4.

[17] Thomsen LL, Miles DW, Happerfield L, Bobrow LG, Knowles RG, Moncada S. Nitric oxide synthase activity in human breast cancer. Br J Cancer 1995; 72:41-4.

[18] Nathan C. Inducible nitric oxide synthase: what difference does it make? J Clin Invest. 1997; 15:2417-23.

[19] Scott DJ, Hull MA, Cartwright EJ, et al. Lack of inducible nitric oxide synthase promotes intestinal tumorigenesis in the Apc(Min/+) mouse. Gastroenterology 2001; 121:889-99.

[20] Reveneau S, Arnould L, Jolimoy G, et al. Nitric oxide synthase in human breast cancer is associated with tumor grade, proliferation rate, and expression of progesterone receptors. Lab Invest 1999; 79:1215-25.

[21] Vakkala M, Kahlos K, Lakari E, Paakko P, Kinnula V, Soini Y. Inducible nitric oxide synthase expression, apoptosis, and angiogenesis in in situ and invasive breast carcinomas. Clin Cancer Res 2000; 6:2408-16.

[22] Loibl S, von Minckwitz G, Weber S, et al. Expression of endothelial and inducible nitric oxide synthase in benign and malignant lesions of the breast and measurement of nitric oxide using electron paramagnetic resonance spectroscopy. Cancer 2002; 95:1191-8.

[23] Xu W, Lizhi L, Loizidou M, Ahmed M, Taylor I, Moncada S, Charles IG. Nitric Oxide Synthase in Human Breast Cancer, A Doubled-Edged Sword? Nitric Oxide 2002; 6: 490.

[24] Vakkala M, Paakko P, Soini Y. eNOS expression is associated with the estrogen and progesterone receptor status in invasive breast carcinoma. Int $\mathrm{J}$ Oncol 2000; 17: 667-71.

[25] Martin JH, Begum S, Alalami O, Harrison A, Scott KW. Endothelial nitric oxide synthase: correlation with histologic grade, lymph node status and estrogen receptor expression in human breast cancer. Tumour Biol 2000; 21:90-7.

[26] Simoncini T, Hafezi-Moghadam A, Brazil DP, Ley K, Chin WW, Liao JK. Interaction of oestrogen receptor with the regulatory subunit of phosphatidylinositol-3-OH kinase, Nature 2000; 407:538-41.

[27] Haynes MP, Sinha D, Russell KS, et al. Membrane estrogen receptor engagement activates endothelial nitric oxide synthase via the PI3-kinase-Akt pathway in human endothelial cells. Circ Res 2000; 87:677-82.

[28] Dimmeler S, Fleming I, Fisslthaler B, Hermann C, Busse $\mathrm{R}$, Zeiher AM. Activation of nitric oxide synthase in endothelial cells by Akt-dependent phosphorylation. Nature 1999; 399:601-5.

[29] Fulton D, Gratton JP, McCabe TJ et al. Regulation of endothelium-derived nitric oxide production by the protein kinase Akt. Nature 1999; 399:597-601.

[30] Garcia-Cardena G, Fan R, Shah V, Sorrentino R, Cirino G, Papapetropoulos A, Sessa WC. Dynamic activation of endothelial nitric oxide synthase by Hsp90. Nature 1998; 392:821-4.

[31] Goligorsky MS, Li H, Brodsky S, Chen J. Relationships between caveolae and eNOS: everything in proximity and the proximity of everything. Am J Physiol Renal Physiol 2002; 283:F1-10.
[32] Ambs S, Merriam WG, Bennett WP, et al. Frequent nitric oxide synthase-2 expression in human colon adenomas: implication for tumor angiogenesis and colon cancer progression. Cancer Res 1998; 58:334-41.

[33] Chhatwal VJ, Ngoi SS, Chan ST, Chia YW, Moochhala SM. Aberrant expression of nitric oxide synthase in human polyps, neoplastic colonic mucosa and surrounding peritumoral normal mucosa. Carcinogenesis 1994; 15: 2081-5.

[34] Cobbs CS, Brenman JE, Aldape KD, Bredt DS, Israel MA. Expression of nitric oxide synthase in human central nervous system tumors. Cancer Res 1995; 55:72730.

[35] Rosbe KW, Prazma J, Petrusz P, Mims W, Ball SS, Weissler MC. Immunohistochemical characterization of nitric oxide synthase activity in squamous cell carcinoma of the head and neck. Otolaryngol Head Neck Surg 1995; 113:541-9.

[36] Wilson KT, Fu S, Ramanujam KS, Meltzer SJ. Increased expression of inducible nitric oxide synthase and cyclooxygenase-2 in Barrett' $\mathrm{s}$ esophagus and associated adenocarcinomas. Cancer Res 1998; 58:2929-34.

[37] Ambs S, Bennett WP, Merriam WG, et al. Vascular endothelial growth factor and nitric oxide synthase expression in human lung cancer and the relation to $\mathrm{p} 53$. Br J Cancer 1998; 78:233-9.

[38] Klotz T, Bloch W, Volberg C, Engelmann U, Addicks K. Selective expression of inducible nitric oxide synthase in human prostate carcinoma. Cancer 1998; 82:1897-903.

[39] Swana HS, Smith SD, Perrotta PL, Saito N, Wheeler MA, Weiss RM. Inducible nitric oxide synthase with transitional cell carcinoma of the bladder. J Urol 1999; 161: 630-4.

[40] Hajri A, Metzger E, Vallat F, et al. Role of nitric oxide in pancreatic tumour growth: in vivo and in vitro studies. Br J Cancer 1998; 78:841-9.

[41] Weninger W, Rendl M, Pammer J, et al. Nitric oxide synthases in Kaposi抯 sarcoma are expressed predominantly by vessels and tissue macrophages. Lab Invest 1998; 78: 949-55.

[42] Jenkins DC, Charles IG, Thomsen LL, et al. Roles of nitric oxide in tumor growth. Proc Natl Acad Sci USA 1995; 92:4392-6.

[43] Ambs S, Merriam WG, Ogunfusika MO, et al. p53 and vascular endothelial growth factor regulate tumor growth of NOS2-expressing human carcinoma cells. Nat Med 1998; 4:1371-6.

[44] Wink DA, Kasprzak KS, Maragos CM, et al. DNA deaminating ability and genotoxicity of nitric oxide and its progenitors. Science 1991; 254:1001-3.

[45] Forrester K, Ambs S, Lupold SE, et al. Nitric oxide induced p53 accumulation and regulation of inducible nitric oxide synthase (NOS2) expression by wild type p53. Proc Natl Acad Sci USA 1996; 93:2442-7.

[46] Ambs S, Hussain SP, Perwez H, Harris C.C. Interactive effects of nitric oxide and the p53 tumor suppressor gene in carcinogenesis and tumor progression. FASEB J 1997; 11:443-8.

[47] Ambs S, Ogunfusika MO, Merriam WG, Bennett WP, Billiar TR, Harris CC. Up-regulation of inducible nitric 
oxide synthase expression in cancer-prone p53 knockout mice. Proc Natl Acad Sci USA 1998; 95:8823-8.

[48] Zhang J, Dawson VL, Dawson TM, Snyder SH. Nitric oxide activation of poly (ADP-ribose) synthetase in neurotoxicity. Science 1994; 263:687-9.

[49] Smith GC and Jackson SP. The DNA-dependent protein kinase. Genes Dev 1999; 13: 916-34.

[50] Xu W, Liu L, Smith GC, Charles IG. Nitric oxide upregulates expression of DNA-PKcs to protect cells from DNA-damaging anti-tumour agents. Nat Cell Biol 2000; 2:339- 45.

[51] Kolb JP. Pro- and anti-apoptotic role of nitric oxide, NO. C R Acad Sci III 2001; 324:413-24.

[52] Culmsee C, Bondada S, Mattson MP. Hippocampal neurons of mice deficient in DNA-dependent protein kinase exhibit increased vulnerability to DNA damage, oxidative stress and excitotoxicity. Brain Res Mol Brain Res 2001; 87:257-62.

[53] Bartunek J, Vanderheyden M, Knaapen M, Tack W, Kockx M, Goethals M. Deoxyribonucleic acid damage/ repairproteins are elevated in the failing human myocardium due to idiopathic dilated cardiomyopathy. J Am Coll Cardiol 2002; 40:1097-103.
[54] Woo RA, McLure KG, Lees-Miller SP, Rancourt DE, Lee PW. DNA-dependent protein kinase acts upstream of p53 in response to DNA damage. Nature 1998; 394:7004.

[55] Murrell W. Nitroglycerin as a remedy for angina pectoris. Lancet 1879; 1:113-5.

[56] Tzeng E, Yoneyama T, Hatakeyama K, Shears LL, 2nd \& Billiar TR. Vascular inducible nitric oxide synthase gene therapy: requirement for guanosine triphosphate cyclohydrolase I. Surgery 1996; 120:315-21.

[57] Lehrman S. Virus treatment questioned after gene therapy death. Nature. 1999; 401:517-8.

[58] Xu W, Liu L, Charles IG. Microencapsulated iNOS-expressing cells cause tumor suppression in mice. FASEB J 2002; 16:213-5.

[59] Read T. Sorensen DR, Mahesparan R, et al Local endostatin treatment of gliomas administered by microencapsulated producer cells. Nat Biotechnol 2001; 19: 29-34.

[60] Hahne M, Rimoldi D, Schroter M, et al. Melanoma cell expression of Fas (Apo-1/CD95) ligand: implications for tumor immune escape. Science 1996; 274:1363-6. 